\title{
Fortification as an effective strategy to bridge iron gaps during complementary feeding
}

\author{
Madhumita Dobe ${ }^{\mathrm{a}}$, Pankaj Garg ${ }^{\mathrm{b}}$, Gaurav Bhalla ${ }^{\mathrm{c}, *}$ \\ a Department of Health Promotion E Education, AIIHEPH, Block-JC-27 \& 27B, Sector-III, Bidhan Nagar (Salt Lake), Kolkata, West Bengal, India \\ ${ }^{\mathrm{b}}$ Department of Neonatology, Sir Ganga Ram Hospital, Rajinder Nagar, New Delhi, India \\ ' Nestle Nutrition, Nestlé House, Jacaranda Marg, DLF Phase 2, Gurgaon 122002, India
}

\section{A R T I C L E I N F O}

\section{Article history:}

Received 16 May 2017

Accepted 1 November 2017

Available online 20 November 2017

\section{Keywords:}

Hidden hunger

Micronutrient deficiency

Iron deficiency

Fortification

Complementary foods

\begin{abstract}
A B S T R A C T
Micronutrient deficiencies (MNDs) during early life are associated with adverse outcomes. Globally, iron deficiency is the most common MND and is particularly common in the first two years of life. Iron is crucial for neurodevelopment, cognition, and immunity. The composition of complementary feeds influences the overall health of an infant. Plant-based complementary foods do not provide enough iron to meet the nutrient needs during 6-23 months of age. Furthermore, the quantities of animal-source foods given to infants are generally inadequate to meet the iron gap. To address this issue, the use of ironfortified complementary foods should be promoted.
\end{abstract}

(c) 2017 INDIACLEN. Published by Elsevier, a division of RELX India, Pvt. Ltd. All rights reserved.

\section{Introduction}

India has the largest proportion of underweight children, almost double compared to that in sub-Saharan Africa. ${ }^{1}$ According to reports of the India Health Report-Nutrition 2015 and National Family Health Survey-3, stunting and wasting rates in children $<5$ years are $38.7 \%, 48 \%$ and $20 \%$ and $15.1 \%$, respectively. ${ }^{2}$

Hidden hunger or micronutrient deficiency, refers to the chronic deficit of essential vitamins and minerals such as iron, zinc, vitamins A and B, iodine, and folic acid. ${ }^{3}$ Iron deficiency is the most common micronutrient deficiency in the world affecting a large number of children in developing countries. ${ }^{4}$ It is particularly common in the first two years of life, due to the maximum requirement of iron during this period. ${ }^{5}$ Globally, iron deficiency is seen in almost 273.2 million children (age: 0-59 months); vitamin A deficiency in 190 million pre-school children; and more than 35 million newborns are at risk of iodine deficiency disorders. ${ }^{6-8}$ The NFHS-4 data evaluated maternal and child health and nutrition in 13 states in India (Andhra Pradesh, Goa, Bihar, Haryana, Madhya Pradesh, Karnataka, Sikkim, Meghalaya, Tripura, Telangana, Uttarakhand, West Bengal, Tamil Nadu) and in 2 Union Territories (Andaman and Nicobar Islands and Puducherry). The NFHS-4 data

\footnotetext{
* Corresponding author at: Nestlé India Ltd. Nestlé House, Jacaranda Marg M Block, DLF City Phase II, National Highway 8, Gurgaon 122 002, India.

E-mail address: Gaurav.Bhalla@IN.nestle.com (G. Bhalla).
}

reveal that more than $50 \%$ of children are anaemic in the 2 Union Territories and 10 of the 13 states evaluated. ${ }^{9}$

Starting in infancy, micronutrient deficiencies continue through adulthood. During infancy and childhood, these deficiencies are associated with low birth weight; higher mortality rate; impaired mental development; increased risk of chronic diseases; frequent infections; inadequate catch-up growth; and reduced productivity.$^{10}$ Iron deficiency, even without anaemia, can affect cognitive, motor, and emotional development, even causing irreversible damage. ${ }^{11}$

Hidden hunger also poses a significant burden on the socioeconomic productivity of a nation. It negatively impacts the working class, in terms of reduced work capacity or lost human capital, lower paid jobs, lifetime earnings, and lower life expectancy. These factors in turn stall national economic development and limit the capacity to develop health and education systems. ${ }^{6}$ The National Damage Assessment Reports from 80 countries estimated that the median loss across all countries, due to micronutrient deficiencies, was $0.8 \%$, and that country-specific losses ranged from $0.2 \%$ in China and Morocco to $2.7 \%$ in Mali. ${ }^{12,13}$ According to a study by Plessow et al., the economic burden of iron-deficiency anaemia (IDA) in children (aged 6-23 months) in India was an estimated 23.8 billion USD, or $1.3 \%$ of the gross domestic product (GDP); and the human burden was an estimated 6.9 million disability-adjusted life years (DALYs), which equals 285 complete lifespans lost every day, or 12 lifespans every hour (Table 1). ${ }^{14,15}$ In another recent trial, Plessow et al. also reported that in large Indian cities, the lifetime social costs of IDA 
Table 1

Social costs of iron deficiency anemia in India (2013) ${ }^{14}$.

\begin{tabular}{|c|c|c|c|c|c|c|c|c|}
\hline & & \multicolumn{3}{|c|}{ Production losses } & \multicolumn{4}{|c|}{ Intangible costs } \\
\hline & & \multicolumn{3}{|c|}{ (million USD) } & \multicolumn{4}{|c|}{ (in 1000 DALYs) } \\
\hline & & Future & Mortality & Total & Current & Future & Mortality & Total \\
\hline \multirow[t]{3}{*}{$6-23$ months } & Rural & & 281 & & 675 & 4139 & 345 & 5159 \\
\hline & Urban & 5730 & 81 & 5811 & 224 & 1389 & 100 & 1713 \\
\hline & All India & & 362 & & 899 & 5528 & 444 & 6871 \\
\hline
\end{tabular}

in 6-23-month-old children amounted to a production loss of 3222 USD and to 726,000 DALYs. $^{16}$

Nutritional interventions to combat hidden hunger can lead to a high return on investments. According to the Copenhagen Consensus Expert Panel (2008), nutritional interventions such as supplementation for children with vitamin $A$ and zinc deficiencies, fortification for iron and iodine deficiencies, and biofortification rank among the top five best investments for economic growth. ${ }^{6}$ Fortification is a highly cost-effective investment, providing extremely good value, with its benefits far outweighing the costs. For example, the cost of salt iodisation per individual per year is as little as 0.05 USD to 0.10 cents USD and is associated with a return on investment of more than 26 USD, with regard to increased productivity and healthcare savings. ${ }^{17}$

The quantity of food consumed by an infant is limited, and hence it is imperative to provide optimum nutrition at every meal. Home-based meals may not be adequate, and can leave gaps when the diet is predominantly vegetarian or if there is increased consumption of nutrients that adversely affect iron absorption. ${ }^{18}$ In this context, and given the pivotal role of iron in neurodevelopment, cognition, and immunity, it is important to provide iron fortification to meet iron gaps during complementary feeding. This article intends to review available evidence to analyse the nutrient gaps in complementary feeding practices in India and provide effective iron-fortification strategies to improve iron consumption during complementary feeding.

\section{Evolution of the new macro role of iron}

Iron plays a vital role in erythropoiesis, haemoglobin and myoglobin formation, gene transcription, oxidation-reduction actions, and cellular enzyme reactions. ${ }^{19}$ Haemoglobin contains almost $60 \%$ of iron in the body. Of the remaining iron content, around $25 \%$ is contained in the mobilisable iron store and $15 \%$ is bound to myoglobin in the muscles and in enzymes involved in oxidation reactions and other cellular functions. ${ }^{18}$

Iron homoeostasis is important for the normal functioning of the immune system. Iron is important for immune cell proliferation and generation of specific immune responses to infection. Although iron deficiency results in proven reversible immunological defects, iron overload can also have negative effects on immune function. ${ }^{20}$ Iron supplements in excess have been associated with an increased risk of infections. ${ }^{21}$ On the contrary, iron-fortified foods provide lower levels of iron than supplements, and are generally considered to be safe. ${ }^{22}$ Hence, a balanced iron status is crucial to determine the fate of infection. ${ }^{20}$ Immune cells and molecules are needed for sculpting the circuitry and influence the activity of the nervous system. Disruption of immune system functioning leads to impairments in neurogenesis and cognition. ${ }^{23}$ Hence, iron status is central for determining immune responses in young children.

In human beings, iron deficiency up to 3 years of age has a significant impact on learning and memory that continues despite treatment of the iron deficiency status. The hippocampus is the central processing area for declarative learning and memory. The developing hippocampus is particularly vulnerable to the direct and indirect effects of early iron deficiency. This increased vulnerability is mainly due to its rapid maturation rate in the late foetal-neonatal period, in addition to the dependence of the maturational processes on iron. The extra-hippocampal effects include synthesis of thyroid hormone and dopamine, and myelination. These hippocampal and extra-hippocampal effects lead to acute and persistent deficits, impacting learning and memory. $^{24}$

The long-term effects of iron-deficiency anaemia have been reported in two cohort studies. ${ }^{25,26}$ The infants enrolled in the studies were characterised based on the iron status, environmental variables, and psychomotor development. At 5 years of age, infants with iron-deficiency anaemia had lower scores on many of the psychometric tests compared with children with higher haemoglobin levels during infancy. A 5-point drop in intellectual quotient (IQ) was reported in both studies, as well as in other tests related to intellectual function. Five points of IQ reflect a significant handicap affecting millions of infants with anaemia worldwide. ${ }^{25}$ Studies have also demonstrated that iron-deficiency anaemia during infancy was associated with poor inhibitory control and slower reaction times when assessed 8-9 years after iron therapy. These findings indicate the long-term effects of early iron-deficiency anaemia on neurodevelopment and cognition. ${ }^{26}$

Infants utilise their iron stores to cover body needs for the first 6 months, after which the stored iron gets depleted and the amount derived from breast milk becomes inadequate. The largest nutrient gap is for iron, during the transition from breastfeeding to complementary feeding; therefore, it is imperative that complementary foods be rich in iron (Fig. 1 ). ${ }^{27}$

\section{Home-made complementary foods fail to meet iron gaps}

Iron stores at birth are sufficient to meet the nutritional needs of the newborn. However, this stored iron is used up by about 6 months of age. Thereafter, complementary foods should provide adequate amounts of iron, to fill the gap. Foods that may promote iron absorption include ascorbic acid, fermented or germinated food products; whereas foods that inhibit iron absorption include

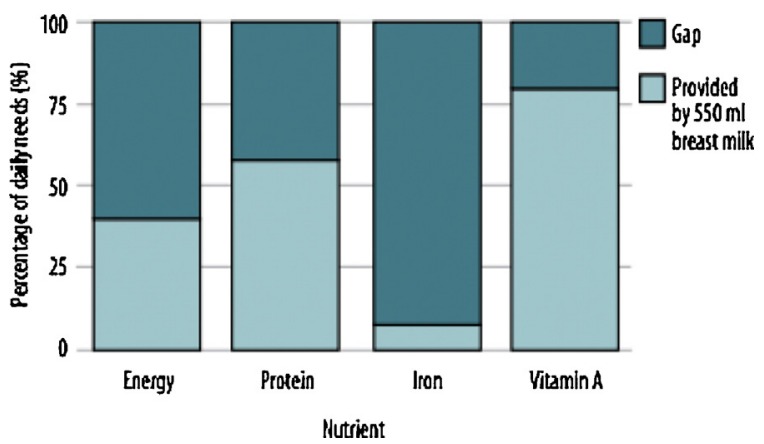

Fig. 1. Gaps to be filled by complementary foods for a breastfed child aged 12-23 months. ${ }^{27}$. 
phytates and polyphenols, calcium in milk, animal proteins, and inositol. ${ }^{28}$ The recommended dietary allowance (RDA) for iron is determined based on the content of iron and its bioavailability in foods. According to the Indian Council for Medical Research, the RDA for iron is $0.23 \mathrm{mg} /$ day for infants aged 1-6 months, $0.73 \mathrm{mg} /$ day for children aged 6-12 months, and $0.451 \mathrm{mg} /$ day for children aged $1-3$ years. $^{29}$

However, it has been shown that a day's complementary food consisting of rice, green leafy vegetables, fish, orange, beans, and porridge along with breast milk, fails to meet an infant's iron requirements. The typical morning meal followed by the midday meal, snacks, and the evening meal containing fish still leaves an iron gap of about $45 \% .^{30}$

\section{Detection of iron deficiency in routine practice: need of the hour}

Timely screening and subsequent testing ensure the prompt diagnosis of iron deficiency and prevention of complications such as cognitive and behavioural effects. ${ }^{31}$ The WHO and UNICEF strongly recommend that in regions where anaemia prevalence exceeds $40 \%$, iron therapy be given; and that it is not cost-effective to screen all children for anaemia. This recommendation is based on the assumption that iron deficiency is prevalent in all children in regions with a high burden of anaemia. However, from a clinical perspective, it is believed that the screening procedure will help to identify children with severe anaemia. According to the nutritional goals of India's Tenth Five-Year Plan, all children should be screened for anaemia. ${ }^{32}$

It is important to note that intervention should not be delayed until screening is performed, since the procedure intends to diagnose only children afflicted with severe anaemia, to provide targeted treatment. ${ }^{32}$

\section{Food fortification: may help bridge nutrient gaps}

Fortification programmes are gaining attention as an effective way of combating malnutrition, in developing countries. ${ }^{33}$ Fortification is a medium-to-long-term approach that requires a suitable food vehicle and organised processing facilities. ${ }^{34}$ As per the 2008 Copenhagen Consensus, food fortification is one of the most cost-effective ways of addressing development challenges. ${ }^{32}$ Current evidence indicates that food fortification is an effective and cost-effective strategy for addressing iron deficiency, especially in infants and young children. ${ }^{35}$

This strategy may work well for large populations with widespread deficiencies of micronutrients, as in India. The high compliance to fortification is due to the ease of substitution of unfortified staples with fortified foods. ${ }^{34}$

Iron fortification can be done through staple food items such as rice, oils, and wheat; condiments such as fish sauce, soy sauce, and sugar; and lastly through processed commercial food items, including infant complementary foods, dairy products, and noodles. ${ }^{36}$ On the contrary, pills, capsules, or syrups containing iron are an effective way to provide iron supplementation. ${ }^{37}$ However, for infants and young children, the use of fortified complementary foods has been shown to be safer and more effective compared to supplements, since the limitations associated with supplementation include the need to purchase iron supplements and the need for a higher degree of treatment compliance. Additionally, they are relatively costlier if the indirect costs (e.g., cost of medicine, doctor's consultation fees, abstinence of parents from work, etc.) are taken into consideration. ${ }^{36,37}$ Fortification is safe because the dose of iron used to fortify foods is much lower than that used in iron supplements. Iron salts recommended by WHO for fortification include ferrous sulphate, ferrous fumarate, ferric pyrophosphate, and electrolytic iron powder. $^{18}$

\section{Benefits of iron fortification}

Food fortification offers many health benefits to the Indian population. A literature survey conducted in India suggested that iron fortification in children led to improvement in iron and haemoglobin status in all the studies. ${ }^{38}$ This report is consistent with data from earlier reviews. ${ }^{38}$ A recent meta-analysis, which included 18 randomised controlled trials and 5468 children, compared the impact of micronutrient-fortified milk and cerealbased products versus similar non-fortified items on children between 6 months and 5 years of age. The use of fortified milk and cereal-based products was more effective in reducing anaemia in young children in developing countries, compared to the use of non-fortified products. Haemoglobin levels significantly increased by $6.2 \mathrm{~g} / \mathrm{L}$ and the risk of anaemia was $50 \%$ lower in children receiving fortified milk or infant cereals. ${ }^{36}$

\section{Iron-fortified cereals help bridge iron gaps during complementary feeding}

Home-based food fortification strategies, such as the use of fortified sprinklers and fortified complementary foods, can be used to deliver nutrients to children in this age group. A study conducted by Sazawal et al. in 2014 in North Delhi, India, and funded by the Thrasher Foundation and the WHO, compared the compliance to two home-based food fortification strategies: fortified complementary foods and home fortification with sprinkles. Fortified complementary foods resulted in a significant increase in mean haemoglobin levels compared to sprinkles and control. The fortified complementary food group showed a $67 \%$ reduction in the proportion of children with anaemia $(\mathrm{Hb}<10 \mathrm{~g} / \mathrm{dL})$ compared to a $27 \%$ reduction in the sprinkle group and a $22 \%$ reduction in the control group. The study showed that fortified complementary foods offer an advantage over home fortification, and are associated with improved iron status. ${ }^{39}$ Using standard health economic models, Detzel et al. estimate that the current consumption levels of fortified food have already reduced the annual burden of IDA by 1.4 billion USD and 0.6 million DALYs, equivalent to 1 lifespan per hour. ${ }^{40}$ According to a report by Prieto et al., consumption of complementary feeds and commercial fortified infant formula showed a strong, positive, and statistically significant association with increased haemoglobin concentration. A significantly positive association was noted between the consumption of fruits rich in vitamin $A$, meat and fish and increased haemoglobin concentrations. ${ }^{15}$

According to WHO, fortified cereals or vitamin-mineral supplements can be given to infants where needed. ${ }^{27}$ The Canadian Paediatric Society recommends that meat, meat alternatives, and iron-fortified cereals can be considered an infant's first complementary foods. ${ }^{41}$ The Indian Academy of Pediatrics encourages the use of iron-fortified foods, iodised salt, vitamin A\&HIPHEN; enriched food, etc. during complementary feeding. ${ }^{42}$

\section{Conclusion}

Iron plays a vital role in several physiological functions of the human body. Iron stores at birth are sufficient to meet the nutritional needs of the newborn; however, these stores are used up by about 6 months of age. Thereafter, complementary foods should provide iron in sufficient quantities to meet the requirements of the growing child. Home-based meals may not bridge all the nutrient gaps, particularly those of iron, during complementary feeding in infants. Food fortification is an assured way of 
addressing micronutrient deficiencies in infants and young children. Use of iron-fortified foods along with home-based foods may be the way forward for improving iron status in infants and young children.

\section{Conflict of interest and funding disclosure}

We declare there is no conflict of interest. Author GB is employee of Nestle India.

\section{Acknowledgements}

We would like to thank Nestle India for support and assistance in development of the manuscript. We would like acknowledge BioQuest Solutions Pvt. Ltd for its manuscript review and editing services.

\section{References}

1. Sahu SK, Kumar SG, Bhat BV, et al. Malnutrition among under-five children in India and strategies for control. I Nat Sci Biol Med. 2015;6:18-23.

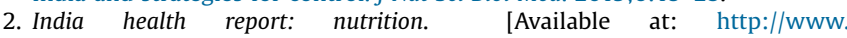
indiaenvironmentportal.org.in/files/file/INDIA-HEALTH-REPORTNUTRITION_2015.pdf Accessed date: 11 February 2015].

3. Muthayya S, Rah JH, Sugimoto JD, Roos FF, Kraemer K, Black RE. The global hidden hunger indices and maps: an advocacy tool for action. PLoS One. 2013;8:e67860.

4. Micronutrient deficiencies. World Health Organization; 2017 [Available at: http://www.who.int/nutrition/topics/ida/en/ Accessed date: 11 February 2016].

5. Conclusions and recommendations of the WHO consultation on prevention and control of iron deficiency in infants and young children in malaria endemic areas. [Available at: http://www.who.int/nutrition/publications/micronutrients/ FNBvol28N4supdec07.pdf Accessed date: 11 February 2016].

6. Global hunger index. [Available at: http://www.ifpri.org/publication/2014global-hunger-index Accessed date: 10 February 2016].

7. World Health Organization. The Global prevalence of anemia in 2011. [Available at: http://apps.who.int/iris/bitstream/10665/177094/1/9789241564960_eng. pdf. Accessed date: 21 March, 2017].

8. UNICEF. Adequately iodized salt can protect children from brain damage, but only three quarters of the world's households are using It. [Updated January, Available at: http://data.unicef.org/topic/nutrition/iodine-deficiency/\# Accessed date: 21 March, 2017].

9. Health ministry releases results from 1st phase of the NFHS-4 survey. [Available at http://pib.nic.in/newsite/PrintRelease.aspx?relid=134608 Accessed date: 11 February 2016]

10. Bailey RL, West KP, Black RE. The epidemiology of global micronutrient deficiencies. Ann Nutr Metab. 2015;66(Suppl. 2):22-33.

11. Black MM. Micronutrient deficiencies and cognitive functioning. I Nutr. 2003;133(11 Suppl. 2):3927S-3931S.

12. Stein AJ, Qaim M. The human and economic cost of hidden hunger. Food Nutr Bull. 2007;28:125-134.

13. UNICEF. Vitamin and mineral deficiency. A global progress report. [Available at: https://www.unicef.org/media/files/vmd.pdf Accessed on 30 January, 2017]

14. Plessow R, Arora NK, Brunner B, et al. Social costs of iron deficiency anemia in 6-59-month-old children in India. PLoS One. 2015;10:e0136581.

15. Prieto A, Detzel P. Association between feeding types and hemoglobin concentration in India poster.

16. Plessow R, Arora NK, Brunner B, Wieser S. Cost-effectiveness of price subsidies on fortified packaged infant cereals in reducing iron deficiency anemia in 623-month-old-children in urban India. PLoS One. 2016;11:e0152800.

17. Global Alliance for Improved Nutrition . Fortifying our future: a snapshot report on food fortification. [Available at: http://www.gainhealth.org/wp-
content/uploads/2015/05/Fortifying-our-Future-A-SnapShot-Report-onFood-Fortification1.pdf].

18. Abbaspour N, Hurrell R, Kelishadi R. Review on iron and its importance for human health. J Res Med Sci. 2014;19:164-174.

19. Radlowski EC, Johnson RW. Perinatal iron deficiency and neurocognitive development. Front Hum Neurosci. 2013;7:585.

20. Das I, Saha K, Mukhopadhyay D, et al. Impact of iron deficiency anaemia on cell-mediated and humoral immunity in children: a case control study. J Nat Sci Biol Med. 2014;5:158-163.

21. Domellof M, Braegger C, Campoy C, et al. Iron requirements of infants and toddlers. JPGN. 2014;58:119-129.

22. Brittenham GM. Safety of iron fortification and supplementation in malariaendemic areas. Nestle Nutr Inst Workshop Ser. 2012;70:117-127.

23. Marin I, Kipnis J. Learning and memory and the immune system. Learn Mem. 2013;20(September):601-606.

24. Fretham SJB, Carlson ES, Georgieff MK. The role of iron in learning and memory. Adv Nutr. 2011;2:112-121.

25. Walter T. Effect of iron-deficiency anaemia on cognitive skills and neuromaturation in infancy and childhood. Food Nutr Bull. 2003;24:S104S110.

26. Algarin C, Nelson CA, Perirao P, Westerlund A, Reyes S, Lozoff B. Iron-deficiency anaemia in infancy and poorer cognitive inhibitory control at age 10 years. Dev Med Child Neurol. 2013;55:453-458.

27. World Health Organization. Infant and young child feeding (iycf) model chapter for textbooks for medical students and allied health professionals. [pp.3-8,19-28, 37-50].

28. Quintaes KD, Cilla A, Barberá R. Iron bioavailability from cereal foods fortified with iron. Austin J Nutr Metab. 2015;2:1021.

29. Indian Council of Medical Research. Nutrient requirements and recommended dietary allowances for children. A report of the expert group of the Indian Council of Medical Research. :208-209.

30. World Health organization. Complementary feeding: family foods for breastfed children. [Available at: http://apps.who.int/iris/bitstream/10665/66389/1/ WHO_NHD_00.1.pdf?ua=1\&ua=1 Accessed on: 18 December 2015].

31. Saba F, Poornima S, Balaji, Varne SRR, Jayashree K. Anemia among hospitalized children at a multispecialty Hospital, Bangalore (Karnataka), India. J Family Med Prim Care. 2014;3:48-53.

32. Kotecha PV. Nutritional anaemia in young children with focus on Asia and India. Indian J Community Med: Off Publ Indian Assoc Prev Soc Med. 2011;36:816.

33. Berry J, Mukherjee P, Shastry GK. Taken with a grain of salt: micronutrient fortification in South Asia. CESifo Econ Stud. 2012;58:422-449.

34. Iron deficiency anaemia. Assessment, prevention, and control. a guide for programme managers. World health organization; 2001.

35. Detzel P, Wieser S. Food fortification for addressing iron deficiency in Filipino children: benefits and cost effectiveness. Ann Nutr Metab. 2015;66(Suppl. 2):35-42.

36. Eichler K, Wieser S, Ruthermann I, Brugger U. Effects of micronutrient fortified milk and cereal food for infants and children: a systematic review. BMC Public Health. 2012:12:506.

37. World Health Organization. Guidelines on food fortification with micronutrients. [Available at: http://apps.who.int/iris/bitstream/10665/43412/1/ 9241594012 eng.pdf?ua=1 Accessed on August 23, 2017].

38. Liu P, Bhatia R, Pachón H. Emory: food fortification in India: a literature review. Indian J Comm Health. 2014;26:59-74.

39. Sazawal S, Dhingra P, Dhingra U, et al. Compliance with home-based fortification strategies for delivery of iron and zinc: its effect on haematological and growth markers among 6-24 months old children in North India. J Health Popul Nutr. 2014;32:217-226.

40. Detzel P., Prieto A. Estimating the contribution on the reduction of the burden of Iron Deficiency Anemia from the current fortification strategy for commercial foods targeted to infants and toddlers in India. Scenarios using systematic review and real world evidence. Abstract No. 250 accepted for ESPGHAN 2016 Athens.

41. Nutrition for healthy term infants: recommendations from birth to 6 months. Available at: http://www.hc-sc.gc.ca/fn-an/nutrition/infant-nourisson/recom/ index-eng.php. Accessed on: 20 August 2015.

42. Infant and young child feeding guidelines. [Available at: http://www. indianpediatrics.net/dec2010/dec-995-1004.htm. Accessed on: 20 August 2015]. 